\title{
Persistent Copulation in Asexual Female Potamopyrgus antipodarum: Evidence for Male Control with Size-Based Preferences
}

\author{
Amanda E. Nelson and Maurine Neiman \\ Department of Biology, University of Iowa, 143 Biology Building, Iowa City, IA 52242-1324, USA
}

Correspondence should be addressed to Amanda E. Nelson, amanda-nelson@uiowa.edu

Received 30 September 2010; Revised 12 January 2011; Accepted 3 February 2011

Academic Editor: Jeremy Marshall

Copyright ( $) 2011$ A. E. Nelson and M. Neiman. This is an open access article distributed under the Creative Commons Attribution License, which permits unrestricted use, distribution, and reproduction in any medium, provided the original work is properly cited.

\begin{abstract}
Transitions from sexual to asexual reproduction provide a useful context for investigating the evolutionary loss of nonfunctional traits. It is often assumed that useless behaviors or structures will degrade, but this process is poorly understood. Potamopyrgus antipodarum is an ancestrally sexual New Zealand freshwater snail characterized by numerous independent transitions to asexual all-female lineages. The availability of multiple independently-derived asexual lineages of various time since derivation from sexual ancestors means that the P. antipodarum system is well-suited for the study of trait loss related to mating behavior and copulation. Here, we asked whether mating behavior in asexual female $P$. antipodarum degrades with increasing asexual lineage age. While copulation frequency did not differ in females from old versus young asexual lineages, post hoc analyses indicated that it was instead positively associated with mean lineage female size. We observed that female $P$. antipodarum take a passive physical role in copulatory interactions, indicating that female behavior may not be a useful variable for detection of sex-related vestigialization in this system. Instead, males seem to be in proximate control of copulation frequencies, meaning that male mating behavior may be a primary determinant of the expression of mating behavior in asexual female P. antipodarum.
\end{abstract}

\section{Introduction}

Vestigialization, the evolutionary loss of formerly useful and presently nonfunctional morphological, molecular, and behavioral traits, is an important evolutionary process that remains poorly understood [1-3]. The multiple independent transitions from sexual to asexual reproduction across eukaryotic phylogeny [4] and the likelihood that mating is costly [5-14] provide a powerful context in which to pose questions regarding rates of vestigialization. For example, we might expect that parthenogenetic lineages that do not need to copulate or be fertilized by another individual to reproduce may experience relaxed selection for the maintenance of sexual structures and behaviors, setting the stage for trait loss $[1,5,15-17]$. Selection may even actively favor the loss of traits related to mating behavior and copulation in asexual lineages if these traits are costly [1-3]. Empirical examples of decay of mating behavior associated with transitions to asexuality include the documentation of increasing reluctance to mate in female Drosophila mercatorum following several generations of artificial selection for parthenogenetic reproduction [18] and the observation of decay of female mating behavior in natural strains of the parasitoid wasp Apoanagyrus divericornis subject to infection-induced thelytokous parthenogenesis [19].

Potamopyrgus antipodarum, a prosobranch snail native to New Zealand freshwater lakes and streams, is an excellent model system in which to examine rates of behavioral vestigialization. First, many $P$. antipodarum populations contain both obligately sexual, dioecious individuals and obligately parthenogenetic females [20,21], such that asexual females often coexist with males in their native populations. Second, asexual $P$. antipodarum lineages are of multiple, independent origins from sexual $P$. antipodarum $[21,22]$ and vary in age from less than 70,000 years since derivation from sexual P. antipodarum ("young") to over 500,000 years 
TABLE 1: Copulation frequency, shell length, and lineage age in asexual cultures.

\begin{tabular}{|c|c|c|c|c|}
\hline Culture & Mean copulation frequency $\pm 1 \mathrm{SD}$ & Mean shell length $\pm 1 \mathrm{SD}$ & Lineage age & $N$ \\
\hline Taylor ${ }^{\mathrm{a}, \mathrm{b}}$ & $0.13 \pm 0.13$ & $4.27 \pm 0.33$ & YOUNG & 14 \\
\hline Mapourika $^{\mathrm{a}}$ & $0.13 \pm 0.18$ & $4.32 \pm 0.31$ & OLD & 13 \\
\hline Denmark A* & $0.15 \pm 0.10$ & $4.30 \pm 0.24$ & OLD & 5 \\
\hline Duluth* & $0.16 \pm 0.37$ & $4.70 \pm 0.22$ & OLD & 4 \\
\hline Okareka ${ }^{\mathrm{a}, \mathrm{b}}$ & $0.18 \pm 0.11$ & $4.37 \pm 0.58$ & OLD & 15 \\
\hline Sarah $^{\mathrm{a}}$ & $0.19 \pm 0.15$ & $4.54 \pm 0.50$ & YOUNG & 14 \\
\hline Poerua & $0.24 \pm 0.15$ & $4.53 \pm 0.21$ & YOUNG & 14 \\
\hline Waikaremoana Lab** & $0.25 \pm 0.15$ & $4.65 \pm 0.47$ & $\mathrm{OLD}^{* *}$ & 19 \\
\hline Evelyn & $0.31 \pm 0.16$ & $4.67 \pm 0.32$ & YOUNG & 13 \\
\hline Waikaremoana Field** & $0.32 \pm 0.15$ & $4.65 \pm 0.42$ & $\mathrm{OLD}^{* *}$ & 19 \\
\hline Tarawera $^{c}$ & $0.35 \pm 0.15$ & $5.09 \pm 0.82$ & OLD & 14 \\
\hline Taupo $^{c}$ & $0.39 \pm 0.21$ & $5.60 \pm 0.61$ & OLD & 15 \\
\hline All females & $0.25 \pm 0.17$ & $4.67 \pm 0.59$ & - & 159 \\
\hline
\end{tabular}

Culture of origin (rank ordered by increasing copulation frequency), mean copulation frequency \pm SD, mean shell length \pm SD, lineage age, and number of individual asexual females used from each culture. "Young" indicates lineages derived from sexual ancestors $<70,000$ years ago, while "old" indicates lineages derived $>500,000$ years ago [23]. * Denotes the only two population names that do not refer to lakes of origin in New Zealand; the ancestor of the Denmark A lineage was collected in Denmark in the early 1990s, and the ancestor of the Duluth lineage was collected in 2007 in Minnesota, USA from

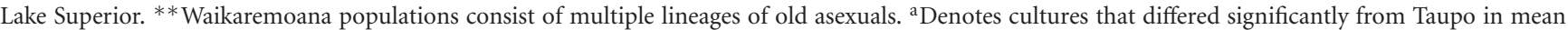
copulation frequency via Bonferroni-corrected chi-square comparisons. ${ }^{b}$ Denotes significant differences in copulation frequency from Tarawera. ${ }^{c}$ Taupo differed significantly in mean length from all cultures except Tarawera ( $t$-tests). All differences are significant at $P<.05$.

since derivation ("old") [23], allowing for the comparison of behavioral consequences of the absence of sex on differential evolutionary time scales. Previous studies showed no difference in copulation frequency of male $P$. antipodarum with sexual versus asexual females from young lineages when males were housed simultaneously with both types of female [24] and no apparent reproductive benefits of copulation to asexual females [25].

Here, our goal was to generate new insights into the persistence of mating behavior in asexual $P$. antipodarum through comparison of copulatory behavior in multiple young and old asexual lineages. We predicted that if mating is sufficiently costly, mating behavior will be degraded in old lineages relative to their younger counterparts. We found that there are no differences in asexual female copulation frequencies based on lineage age. Instead, post hoc analysis shows that asexual female copulation frequency increases with female body size and suggests that male $P$. antipodarum are in physical control of copulatory behavior. Male control of copulation would mean that copulation frequencies do not represent physical actions on the part of females and implies that copulation frequencies may not reflect female evolutionary change or lack thereof.

\section{Materials and Methods}

2.1. Experimental Methods. We haphazardly selected 170 sexually mature ( $>3 \mathrm{~mm}$ in length $[26,27])$ asexual female $P$. antipodarum from twelve lab-raised lineages or fieldcollected cultures that consisted of either young $(<70,000$ years since derivation from sexual ancestors) or old ( $>500,000$ years since derivation from sexual ancestors) asexual clades (Table 1). Time since derivation from sexual ancestors was previously established for source populations through phylogenetic analysis of cytochrome b mtDNA haplotypes [23]. Lab-raised and field-collected subsets of snails of common origin will hereafter be referred to as "cultures." To control for prior exposure to males, field-collected females were selected from samples with $<5 \%$ males, indicating that males-and thus sexuals - are rare in source populations $[28,29]$. We haphazardly collected sexually mature males (possessing a visible penis [30]) from a culture consisting of three inbred sexual lineages derived from a single New Zealand lake (Lake Alexandrina) and three cultures from New Zealand lakes with high relative frequencies of sexual $P$. antipodarum (Lakes Kaniere, Rotoroa, and Wairarapa). We used 16-56 males from each of these cultures according to male availability. We also included 15 males (individual identity unknown) drawn from a mixture of inbred Lake Alexandrina cultures and a culture from Lake Kaniere. We recorded the culture of origin for all $P$. antipodarum and used nail polish to make a culture-specific mark on each individual.

Each asexual female was housed separately in a $0.95 \mathrm{~L}$ plastic cylindrical cup containing $\sim 700 \mathrm{~mL}$ of water. We added an $\sim 1 \mathrm{~cm}^{3}$ piece of chalk to each cup as a source of dietary calcium. Each snail was fed $1 \mathrm{~g} / \mathrm{L}$ Spirulina (a common lab food for $P$. antipodarum) $3 \times$ weekly. Cups were maintained at $16^{\circ} \mathrm{C}$ on a $12: 12 \mathrm{hr}$ light:dark cycle. Females that died were replaced for the first week only, resulting in 159 females at experiment end. One male was placed in each cup and redistributed to a different cup ("rotated") twice weekly, so that male-female pairs from all possible culture combinations were observed and to control for variation in male mating behavior across cultures. Five males of mixed 
Alexandrina/Kaniere origin were distributed randomly after all other males had been placed in containers. The fourweek experiment included eight rotations (two per week), each constituting a single "copulation opportunity" for a distinct male-female pair, resulting in a total of 1272 pairwise rotations (or "opportunities"). In other words, each distinct snail pair had a 2.5 day "opportunity" to copulate.

2.2. Observation of Courtship and Copulatory Behavior. Specific behaviors observed repeatedly and involving physical contacts between males and females were recorded (see Supplemental Table 1 in Supplementary Material available online at doi: 10.4061/2011/439046) five days a week for four weeks at approximately $830,1100,1300$, and 1500 hours. Each observation lasted 15-20 minutes, which was the time required to assess the behaviors for each pair. While we recorded four distinct behaviors, analyses focused solely on copulation as this behavior was most explicitly defined and the only behavior observed with sufficient frequency to be amenable to meaningful statistical interpretation (supplemental Table 2). Copulation in P. antipodarum has been previously specified as the assumption of an apertureto-aperture position maintained over $\sim 20-90$ minutes [25]. All 416 observed aperture to aperture contacts occurred with the male situated in a dextralateral position on the female's shell, consistent with Fretter's [31] observations of specific mating positions in other prosobranch taxa. This distinct position was classified as copulation. Further, each observation of the copulatory position was examined using 10x magnification in order to confirm that body-to-body contact was occurring between male-female pairs.

The other three behaviors included "resistance," defined as a female mounted by a male twisting so that her body made an abrupt radial motion. The same behavior was observed when males housed without females were mounted by other males. The behavior we termed "riding" was defined as a male mounted on a female shell away from her aperture and remaining stationary while the female foraged. "Checking" was defined as the male actively, often (relatively) rapidly circling the female's shell.

2.3. Statistical Analysis. Copulation data were discrete and left skewed, such that nonparametric analyses were required. We analyzed copulation frequencies in terms of the proportion of copulation opportunities (as defined above) in which copulation was observed within cultures. We performed $2 \times 2$ chi-square tests to determine whether there were differences in the proportion of opportunities in which members of young versus old asexual cultures copulated. We also performed $2 \times 2$ chi-square tests to detect differences in copulation duration and repetition, respectively, between young and old asexual cultures, but these results are not included as they were qualitatively the same as results using the proportion of opportunities in which copulation was observed. We also used chi-square tests within old cultures $(2 \times 8)$, within young cultures $(2 \times 4)$, among all cultures combined $(2 \times 12)$, and pairwise between all combinations of cultures $(662 \times 2$ tests, Bonferroni-corrected threshold at
$P=.0008)$ in order to compare variation between old and young cultures to overall variation in copulation frequency. All chi-square comparisons were performed by hand.

2.4. Post Hoc Analysis. We observed marked variation across asexual female cultures in both copulation frequency and size. Since female $P$. antipodarum possess notable heritable variation in shell size [32], and because males from other snail taxa prefer to copulate with larger females $[33,34]$, we then asked whether across-culture size differences affected copulation frequencies. We quantified size in each female at the end of the experiment by measuring shell length (longest dorsal distance in $\mathrm{mm}$ from aperture to apex of shell) and shell width ( $\mathrm{mm}$ across widest portion of shell). We also used these data to quantify "obesity" (width:length), following Winterbourn [35]. We used two-tailed Spearman's rho coefficients in SPSS to detect correlations (across all pairwise variable combinations) between mean culture copulation frequency and mean culture length, width, and obesity. Because mean length and width were positively correlated with mean copulation frequency and mean obesity was not (see results), we used stepwise linear regression to determine whether length and/or width were significant predictors of copulation frequency. Next, we used Bonferroni-corrected pairwise Student's $t$-tests to quantify culture-level differences in female length (66t-tests for each parameter, Bonferroni threshold at $P=.0008)$.

478 out of 511 observed physical contacts between males and asexual females consisted of apparent physical activity only on the part of the male (see Supplemental Tables 1-2), suggesting that male $P$. antipodarum may control copulation frequency. Chi-square tests were used to detect differences in copulation frequency across all four male cultures $(2 \times 4$ test $)$ and between pairs of male cultures (6 $2 \times 2$ tests, Bonferroni threshold at $P=.008$ ). Data from the mixed Alexandrina/Kaniere origin males were not included in these analyses because specific male origins were unknown. Among both males and females, we observed marked differences between cultures with the highest and lowest overall mean copulation frequencies. These differences provided an opportunity to compare the effects of male versus female culture on copulation frequencies. In order to do this, we used the highest and lowest relative mean copulation frequencies for pairwise comparison of male-female culture combinations in a Scheirer-Ray-Hare extension of a Kruskal-Wallis test. If males control copulation frequency, we expected to find a marked effect of male culture and little or no effect of female culture on observed pairwise copulation frequencies.

\section{Results}

We observed 416 copulations involving 159 females over the course of 314 copulation opportunities (as defined above) resulting in copulation. On average, females copulated $2.62 \pm 2.11 \mathrm{SD}$ times. This value is similar in magnitude to observations reported in Neiman and Lively (2005) in which mean number of copulations for sexual and asexual 


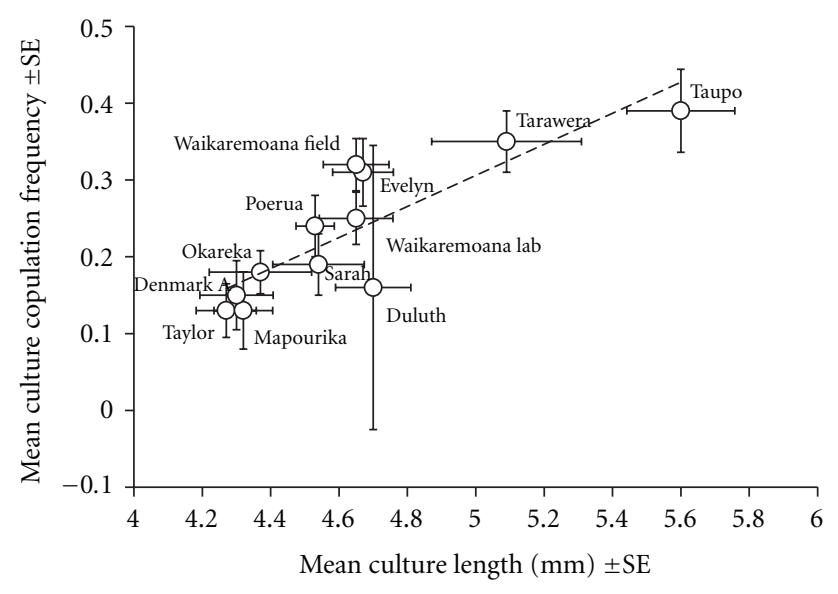

Figure 1: Plot of mean asexual female culture copulation frequency \pm SE versus mean culture shell length \pm SE. Mean copulation frequency increases with mean shell length for asexual females.

females were $3.49 \pm 0.47 \mathrm{SD}$ and $2.58 \pm 0.40 \mathrm{SD}$, respectively [24]. 78.61\% of copulations lasted 20 minutes to 1.5 hours, within the range reported in Neiman and Lively (2005). $14.66 \%$ of copulations lasted from two to four hours, $4.33 \%$ lasted between four and six hours, and 1.92\% lasted six or more hours. Our observations of copulation durations substantially longer than those in the previous study may be due to larger sample sizes revealing greater variation in this behavior. Another nonmutually exclusive explanation may be differences in experimental design (male-female pairs in our study versus multiple males housed with multiple females in Neiman and Lively (2005)) [24].

There were no significant differences in the proportion of opportunities in which females from old versus young cultures copulated $\left(\chi^{2}=3.15, P=.0759\right.$, df $=1$; Table 1$)$. In contrast, there was marked across-lineage variance in copulation frequency for old asexual female cultures $\left(\chi^{2}=\right.$ $32.50, P=.0003$, df $=7$ ), young asexual female cultures $\left(\chi^{2}=10.84, P=.0126, \mathrm{df}=3\right)$, and across all asexual female cultures $\left(\chi^{2}=47.33, P<.00001, \mathrm{df}=11\right)$.

Copulation frequency among all asexual female cultures was positively correlated with both length $(\rho=0.824, P=$ $.001, n=12$; Figure 1$)$ and width $(\rho=0.639, P=.025$, $n=12)$. Length and width were not correlated $(\rho=0.481$, $P=.114, n=12$ ). Obesity was correlated only with width ( $\rho=0.931, P<.001, n=12)$, not with copulation frequency ( $\rho=0.351, P=.263, n=12$ ). While length significantly and positively affected copulation frequency in a stepwise linear regression $(\beta=0.732, P=.039, n=12)$, no further analysis was conducted with width since it was not associated with copulation frequency $(\beta=0.088, P=.778, n=12)$. Bonferroni-corrected $t$-tests showed that one female culture, Taupo, was significantly longer than all other female cultures except Tarawera (Table 1), such that the longest cultures also exhibited the highest mean copulation frequencies relative to other cultures. The mean length of females from old cultures $(4.75 \mathrm{~mm} \pm 0.67 \mathrm{SD})$ was similar to that of

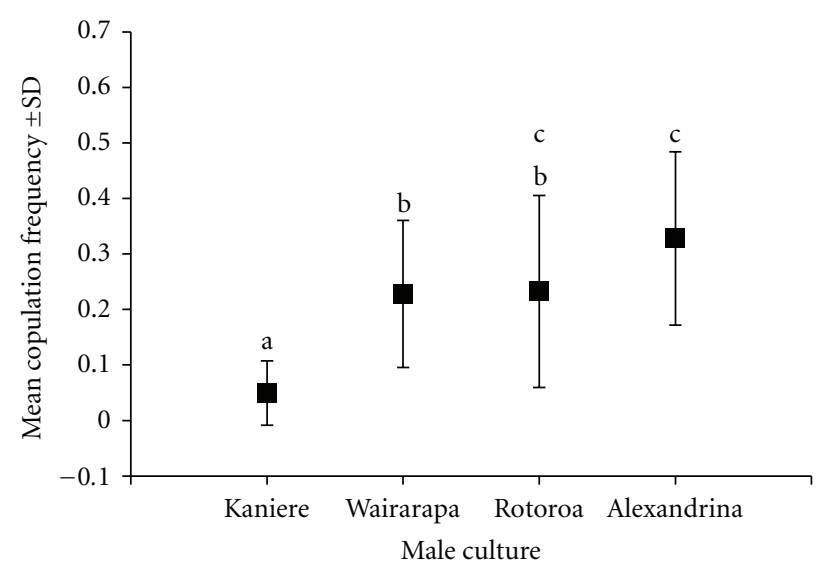

Figure 2: Differences in mean copulation frequency ( \pm 1 standard deviation) for all four male cultures. Letters in common above error bars indicate $P>.05$ in a Bonferroni-corrected chi-square test for differences in copulation frequency. Bonferroni-adjusted $P$ values for significant differences are as follows: $P(\mathrm{a} / \mathrm{b})=.0012-.00012$, $P(\mathrm{~b} / \mathrm{c})=.009$, and $P(\mathrm{a} / \mathrm{c})=.00006$.

young cultures $(4.50 \mathrm{~mm} \pm 0.38 \mathrm{SD})$ and the longest cultures differed from the shortest cultures irrespective of lineage age (Table 1). Across all cultures, shell length was a significant predictor of copulation frequency, but only between the low and high ends of the distribution of female shell lengths (Table 1; Figure 1). Females from Mapourika, Taylor, and Okareka represented the lowest mean copulation frequency and females from Taupo, Tarawera, and Waikaremoana Field represented the highest mean copulation frequency cultures. These were the cultures we used for Scheirer-Ray-Hare analysis. Denmark A and Duluth cultures were excluded from this analysis due to small sample sizes (Table 1).

There were significant differences in copulation frequency among male cultures $\left(\chi^{2}=42.91, P<.00001\right.$, df $=3)$. Alexandrina and Kaniere males differed most in copulation frequency (Alexandrina having the highest overall mean copulation frequency and Kaniere the lowest, Figure 2). These two male cultures were included in the Scheirer-Ray-Hare test. This test revealed an effect of male culture on mean pairwise copulation frequency at high and low extremes of copulation frequency $(\mathrm{SS}=75, \mathrm{H}=5.98$, $P=.015, \mathrm{df}=1)$ but showed no effect of female culture ( $\mathrm{SS}=12.12, \mathrm{H}=0.97, P=.325, \mathrm{df}=1)$ and no interaction between male and female culture $(\mathrm{SS}=1.38, \mathrm{H}=0.11$, $P=.740, \mathrm{df}=1)$.

\section{Discussion}

There was no apparent effect of lineage age on copulation frequency in female asexual $P$. antipodarum. Instead, differences in copulation frequency seem primarily to be a function of differences in female shell length (Figure 1). Further analyses suggest that male rather than female copulatory tendencies might largely determine copulation frequencies and that female size differences might provide a basis for male mating preferences. 
In the absence of a lineage age effect, we find no evidence of vestigialization of reproductive behaviors. In fact, the significant variation in copulation frequency within age classes shows that there is considerably more variation within than between old and young cultures. Nonmutually exclusive explanations for the apparent lack of a role for asexual lineage age in determining female copulatory behavior include insufficient time for neutral mutation and/or natural selection to degrade the genetic basis of useless or costly female reproductive behaviors, that mating behavior is maintained by selection, or that apparently old asexual lineages have an undiscovered recent sexual ancestor (reviewed in [36]). It is also possible that maintaining mechanisms of mate choice, such as the avoidance of undesirable mates, may be costly to females. Some have even speculated that receptivity to mating may actually increase in asexual females depending on which sex-related genes (i.e., genes associated with mating versus those associated with avoidance of mating) undergo relaxed selection [37].

It is also possible that asexual female P. antipodarum gain nonreproductive benefits from copulation, as in several invertebrate taxa. For instance, seminal fluid includes components that increase female longevity in the field cricket, Gryllus lineaticeps [38], and the bedbug, Cimex lectilarius [39]. Multiply-mated female Callobruchus maculatus (seed beetles) show higher tolerance of starvation conditions [10, 40], but under normal conditions this benefit does not overcome a cost of harassment by males [10]. Traits that have lost a given function may be maintained by selection if a novel function is gained that increases fitness [1]. Under a model of antagonistic sexual coevolution [41], it is expected that internal female reproductive structures, such as sperm storage organs, are more likely to be modified by natural or sexual selection than external female genitalia [42]. Dillon [43] observed that structures originally associated with sperm storage are maintained in asexual P. antipodarum and assumed that these structures retain their original function. However, it has been suggested that one such structure, the bursa copulatrix, is modified in asexual female P. antipodarum to function for digestion of waste materials [44]. If the bursa copulatrix serves a digestive function in asexual female $P$. antipodarum and still receives sperm, it could provide the basis for a nutritive benefit of copulation. However, in taxa where putative nutritive benefits of ejaculate components have been extensively studied, the proximate mechanism by which such benefits are conferred remains unclear (e.g., [10]).

Post hoc comparisons indicating that male rather than female culture-level tendencies affect mean copulation frequencies points to male control as one possible determinant of relative differences in asexual female copulation frequencies. Further, copulation in P. antipodarum occurs via male mounting of the female shell, a mechanism which is thought to confer greater control to the snail on top [45]. Regardless of the evolutionary implications of persistent copulatory behavior in asexual female $P$. antipodarum, male control of copulation implies male control of copulation frequencies [46]. This would mean that copulatory behavior may not be a useful metric by which to detect sex-related trait changes in females. However, the proximate physical mechanisms of mating observed herein may belie an important role for females; chemical signaling via mucus may play an important role in prosobranch snail mating [31]. In other words, female $P$. antipodarum may control copulation frequencies via biochemical or physiological traits not measured in this experiment.

The finding that longer females engage in more copulation has important implications for copulatory control. Female $P$. antipodarum show a positive relationship between size and fecundity $[47,48]$. This, along with the observed effect of length on copulation frequency in P. antipodarum females, suggests that male mating behavior may be influenced by length as a signal for fecundity. That length most affects copulation frequency at the high and low extremes of size is not without precedent. For example, in guppies (Poecilia reticulata), male mating preference based on size is markedly stronger as the relative size difference between females increases [49]. Male preference for larger mates in Drosophila melanogaster reduces variance in female relative fitness because larger, otherwise more fecund females suffer fitness costs from increased harassment by males relative to their smaller counterparts [12].

It is a standard assumption that females are more likely to be the "choosy" gender [50], yet male preferences, though little studied, may dominate copulation dynamics $[12,51]$. If male P. antipodarum are both choosy and in proximate control of copulation, why do they continue to copulate with asexual females? One possibility is that males basing mating preference on female size cannot discriminate between sexual and asexual female $P$. antipodarum, which do not consistently differ in size [32]. This phenomenon has been documented in hybridogenetic water frogs, in which indiscriminant male mating behavior is more likely to persist when sexual and asexual (hybridogenetic) females are of similar size [51]. Alternately, males may be doing the "best of a bad job" by balancing the cost of discrimination versus the cost of futile mating [52].

One caveat of our study was that in only using asexual females from all-asexual source populations, we were unable to ask whether sympatry with sexual males and/or females may drive differences in asexual female copulation frequencies. We did, however, use males from source populations that vary widely in their proportions of asexual females. Interestingly, the male culture that copulated most with asexual females (Alexandrina) came from a source population with a high relative proportion of asexual females (50\%). Conversely, the male culture with the lowest copulation frequency with asexual females (Kaniere) was from a nearly all-sexual source population. Likewise, the two male cultures with intermediate copulation frequencies (Wairarapa and Rotoroa) came from source populations with $\sim 10 \%$ asexuals (Neiman, unpublished). That males with greater prior exposure to asexual females copulated with these females more often is counter to the prediction that males are more likely to discriminate when the likelihood of pairing with an undesirable female is higher [52].

The persistence of copulation between male and asexual female $P$. antipodarum appears on the surface to be 
maladaptive for both. Our results indicate that broad assumptions about circumstances favoring vestigialization of characters may belie very complex organismal biology. Potamopyrgus antipodarum as a system reflects the dynamic behavioral and morphological factors that may influence reproductive biology. Far more detailed observation and analysis is needed in order to disentangle the evolutionary forces at work in this unique and interesting system.

\section{Acknowledgments}

Thanks are due to the Guest Editor, Dr. Jeremy Marshall, and two anonymous reviewers for constructive and insightful comments on our paper. The authors thank members of the Neiman laboratory for logistic support and comments on an earlier version of the paper. Thanks are due to Christina Schiltz for edits, moral support, and helping to set up this experiment. Thanks are also due to Claire Tucci for help with our experimental procedure, and Dr. Stephen Hendrix for editorial advice. Thanks also are due to Dr. Jonathan Poulton, the University of Iowa Honors Program, and the University of Iowa, Department of Biology.

\section{References}

[1] D. C. Lahti, N. A. Johnson, B. C. Ajie et al., "Relaxed selection in the wild," Trends in Ecology and Evolution, vol. 24, no. 9, pp. 487-496, 2009.

[2] D. W. Fong, T. C. Kane, and D. C. Culver, "Vestigialization and loss of nonfunctional characters," Annual Review of Ecology and Systematics, vol. 26, no. 1, pp. 249-268, 1995.

[3] M. E. Dorken, K. J. Neville, and C. G. Eckert, "Evolutionary vestigialization of sex in a clonal plant: selection versus neutral mutation in geographically peripheral populations," Proceedings of the Royal Society B, vol. 271, no. 1555, pp. 23752380, 2004.

[4] M. Neiman, S. Meirmans, and P. G. Meirmans, "What can asexual lineage age tell us about the maintenance of sex?" Annals of the New York Academy of Sciences, vol. 1168, pp. 185200, 2009.

[5] M. Daly, "The cost of mating," The American Naturalist, vol. 112, no. 986, pp. 771-774, 1978.

[6] A. E. Magurran and B. H. Seghers, "A cost of sexual harassment in the guppy, Poecilia reticulata," Proceedings of the Royal Society B, vol. 258, no. 1351, pp. 89-92, 1994.

[7] S. F. Chenoweth, D. Petfield, P. Doughty, and M. W. Blows, "Male choice generates stabilizing sexual selection on a female fecundity correlate," Journal of Evolutionary Biology, vol. 20, no. 5, pp. 1745-1750, 2007.

[8] D. J. Hosken and T. A. R. Price, "Genital evolution: the traumas of sex,” Current Biology, vol. 19, no. 13, pp. R519-R521, 2009.

[9] P. W. Bateman, J. W. H. Ferguson, and C. A. Yetman, "Courtship and copulation, but not ejaculates, reduce the longevity of female field crickets (Gryllus bimaculatus)," Journal of Zoology, vol. 268, no. 4, pp. 341-346, 2006.

[10] M. den Hollander and D. T. Gwynne, "Female fitness consequences of male harassment and copulation in seed beetles, Callosobruchus maculatus," Animal Behaviour, vol. 78, no. 5, pp. 1061-1070, 2009.
[11] L. Gay, P. E. Eady, R. Vasudev, D. J. Hosken, and T. Tregenza, "Costly sexual harassment in a beetle," Physiological Entomology, vol. 34, no. 1, pp. 86-92, 2009.

[12] T. A.F. Long, A. Pischedda, A. D. Stewart, and W. R. Rice, "A cost of sexual attractiveness to high-fitness females," PLoS Biology, vol. 7, no. 12, Article ID e1000254, 2009.

[13] I. Schlupp, R. M. Knab, and M. J. Ryan, "Sexual harassment as a cost for molly females: bigger males cost less," Behaviour, vol. 138, no. 2, pp. 277-286, 2001.

[14] K. U. Heubel and M. Plath, "Influence of male harassment and female competition on female feeding behaviour in a sexual-asexual mating complex of mollies (Poecilia mexicana, P. formosa)," Behavioral Ecology and Sociobiology, vol. 62, no. 11, pp. 1689-1699, 2008.

[15] H. J. Muller, "The Darwinian and modern conceptions of natural selection," Proceedings of the American Philosophical Society, vol. 93, no. 6, pp. 459-470, 1949.

[16] H. L. Carson, L. S. Chang, and T. W. Lyttle, "Decay of female sexual behavior under parthogenesis," Science, vol. 218, no. 4567, pp. 68-70, 1982.

[17] M. Neiman, "Physiological dependence on copulation in parthenogenetic females can reduce the cost of sex," Animal Behaviour, vol. 67, no. 5, pp. 811-822, 2004.

[18] H. Ikeda and H. L. Carson, "Selection for mating reluctance in females of a diploid parthenogenetic strain of Drosophila mercatorum," Genetics, vol. 75, no. 3, pp. 541-555, 1973.

[19] J. W. A. M. Pijls, H. J. van Steenbergen, and J. J. M. van Alphen, "Asexuality cured: the relations and differences between sexual and asexual Apoanagyrus diversicornis," Heredity, vol. 76, no. 5, pp. 506-513, 1996.

[20] C. Wallace, "Parthenogenesis, sex and chromosomes in Potamopyrgus," Journal of Molluscan Studies, vol. 58, no. 2, pp. 93107, 1992.

[21] M. F. Dybdahl and C. M. Lively, "Diverse, endemic and polyphyletic clones in mixed populations of a freshwater snail (Potamopyrgus antipodarum)," Journal of Evolutionary Biology, vol. 8, no. 3, pp. 385-398, 1995.

[22] M. Neiman and C. M. Lively, "Pleistocene glaciation is implicated in the phylogeographical structure of Potamopyrgus antipodarum, a New Zealand snail," Molecular Ecology, vol. 13, no. 10, pp. 3085-3098, 2004.

[23] M. Neiman, J. Jokela, and C. M. Lively, "Variation in asexual lineage age in Potamopyrgus antipodarum, a New Zealand snail," Evolution, vol. 59, no. 9, pp. 1945-1952, 2005.

[24] M. Neiman and C. M. Lively, "Male New Zealand mud snails (Potamopyrgus antipodarum) persist in copulating with asexual and parasitically castrated females," American Midland Naturalist, vol. 154, no. 1, pp. 88-96, 2005.

[25] M. Neiman, "Embryo production in a parthenogenetic snail (Potamopyrgus antipodarum) is negatively affected by the presence of other parthenogenetic females," Invertebrate Biology, vol. 125, no. 1, pp. 45-50, 2006.

[26] D. C. Richards and D. C. Shinn, "Intraspecific competition and development of size structure in the invasive snail Potamopyrgus antipodarum (Gray, 1853)," American Malacological Bulletin, vol. 19, no. 1-2, pp. 33-37, 2004.

[27] M. F. Dybdahl and S. L. Kane, "Adaptation vs. phenotypic plasticity in the success of a clonal invader," Ecology, vol. 86, no. 6, pp. 1592-1601, 2005.

[28] J. A. Fox, M. F. Dybdahl, J. Jokela, and C. M. Lively, "Genetic structure of coexisting sexual and clonal subpopulations in a freshwater snail (Potamopyrgus antipodarum)," Evolution, vol. 50, no. 4, pp. 1541-1548, 1996. 
[29] C. M. Lively and J. Jokela, "Temporal and spatial distributions of parasites and sex in a freshwater snail," Evolutionary Ecology Research, vol. 4, no. 2, pp. 219-226, 2002.

[30] M. Haase, "The radiation of hydrobiid gastropods in New Zealand: a revision including the description of new species based on morphology and mtDNA sequence information," Systematics and Biodiversity, vol. 6, no. 1, pp. 99-159, 2008.

[31] V. Fretter, "Prosobranchs," in The Mollusca, Volume 7: Reproduction, A. S. Tompa, N. H. Verdonk, and J. A. M. van den Biggelaar, Eds., Academic Press, Orlando, Fla, USA, 1984.

[32] J. Jokela, C. M. Lively, M. F. Dybdahl, and J. A. Fox, "Evidence for a cost of sex in the freshwater snail Potamopyrgus antipodarum," Ecology, vol. 78, no. 2, pp. 452-460, 1997.

[33] O. V. Ambrogio and J. A. Pechenik, "Do sex-changing male snails use mate choice to get a jump on their "size advantage"?" Marine Biology, vol. 156, no. 10, pp. 2173-2180, 2009.

[34] J. M. Koene, K. Montagne-Wajer, and A. Maat, "Aspects of body size and mate choice in the simultaneously hermaphroditic pond snail Lymnaea stagnalis," Animal Biology, vol. 57, no. 2, pp. 247-259, 2007.

[35] M. Winterbourn, "The New Zealand species of Potamopyrgus (Gastropoda: Hydrobiidae),” Malacologia, vol. 10, pp. 283321, 1970.

[36] A. M. Schurko, M. Neiman, and J. M. Logsdon, "Signs of sex: what we know and how we know it," Trends in Ecology and Evolution, vol. 24, no. 4, pp. 208-217, 2009.

[37] K. Kraaijeveld, P. Franco, B. M. Reumer, and J. J. M. van Alphen, "Effects of parthenogenesis and geographic isolation on female sexual traits in a parasitoid wasp," Evolution, vol. 63, no. 12, pp. 3085-3096, 2009.

[38] W. E. Wagner, R. J. Kelley, K. R. Tucker, and C. J. Harper, "Females receive a life-span benefit from male ejaculates in a field cricket," Evolution, vol. 55, no. 5, pp. 994-1001, 2001.

[39] K. Reinhardt, R. A. Naylor, and M. T. Siva-Jothy, "Ejaculate components delay reproductive senescence while elevating female reproductive rate in an insect," Proceedings of the National Academy of Sciences of the United States of America, vol. 106, no. 51, pp. 21743-21747, 2009.

[40] C. W. Fox, "Multiple mating, lifetime fecundity and female mortality of the bruchid beetle, Callosobruchus maculatus (Coleoptera: Bruchidae)," Functional Ecology, vol. 7, no. 2, pp. 203-208, 1993.

[41] M. Andersson, Sexual Selection, Princeton University Press, Princeton, NJ, USA, 1994.

[42] D. Joly and M. Schiffer, "Coevolution of male and female reproductive structures in Drosophila," Genetica, vol. 138, no. 1, pp. 105-118, 2009.

[43] R. T. Dillon, The Ecology of Freshwater Molluscs, Cambridge University Press, Cambridge, UK, 2000.

[44] V. Fretter and A. Graham, British Prosobranch Molluscs: Their Functional Anatomy and Ecology, Ray Society, London, UK, 1962.

[45] T. Asami, R. H. Cowie, and K. Ohbayashi, "Evolution of mirror images by sexually asymmetric mating behavior in hermaphroditic snails," The American Naturalist, vol. 152, no. 2, pp. 225-236, 1998.

[46] M. Ridley, "The control and frequency of mating in insects," Functional Ecology, vol. 4, no. 1, pp. 75-84, 1990.

[47] E. Gaino, F. Scoccia, T. Lancioni, and A. Ludovisi, “The invader mudsnail Potamopyrgus antipodarum in the Tiber River basin (Central Italy)," Italian Journal of Zoology, vol. 75, no. 3, pp. 253-261, 2008.
[48] T. M. Tibbets, A. C. Krist, R. O. Hall Jr., and L. A. Riley, "Phosphorus-mediated changes in life history traits of the invasive New Zealand mudsnail (Potamopyrgus antipodarum)," Oecologia, vol. 163, no. 3, pp. 549-559, 2010.

[49] L. D. Dosen and R. Montgomerie, "Female size influences mate preferences of male guppies," Ethology, vol. 110, no. 3, pp. 245-255, 2004.

[50] M. Daly and M. Wilson, Sex, Evolution, and Behavior: Adaptations for Reproduction, Duxbury Press, Belmont, Calif, USA, 1978.

[51] D. S. Schmeller, R. O'Hara, and H. Kokko, "Male adaptive stupidity: male mating pattern in hybridogenetic frogs," Evolutionary Ecology Research, vol. 7, no. 7, pp. 1039-1050, 2005.

[52] T. J. Kawecki, "Unisexual/bisexual breeding complexes in Poeciliidae: why do males copulate with unisexual females?" Evolution, vol. 42, no. 5, pp. 1018-1023, 1988. 

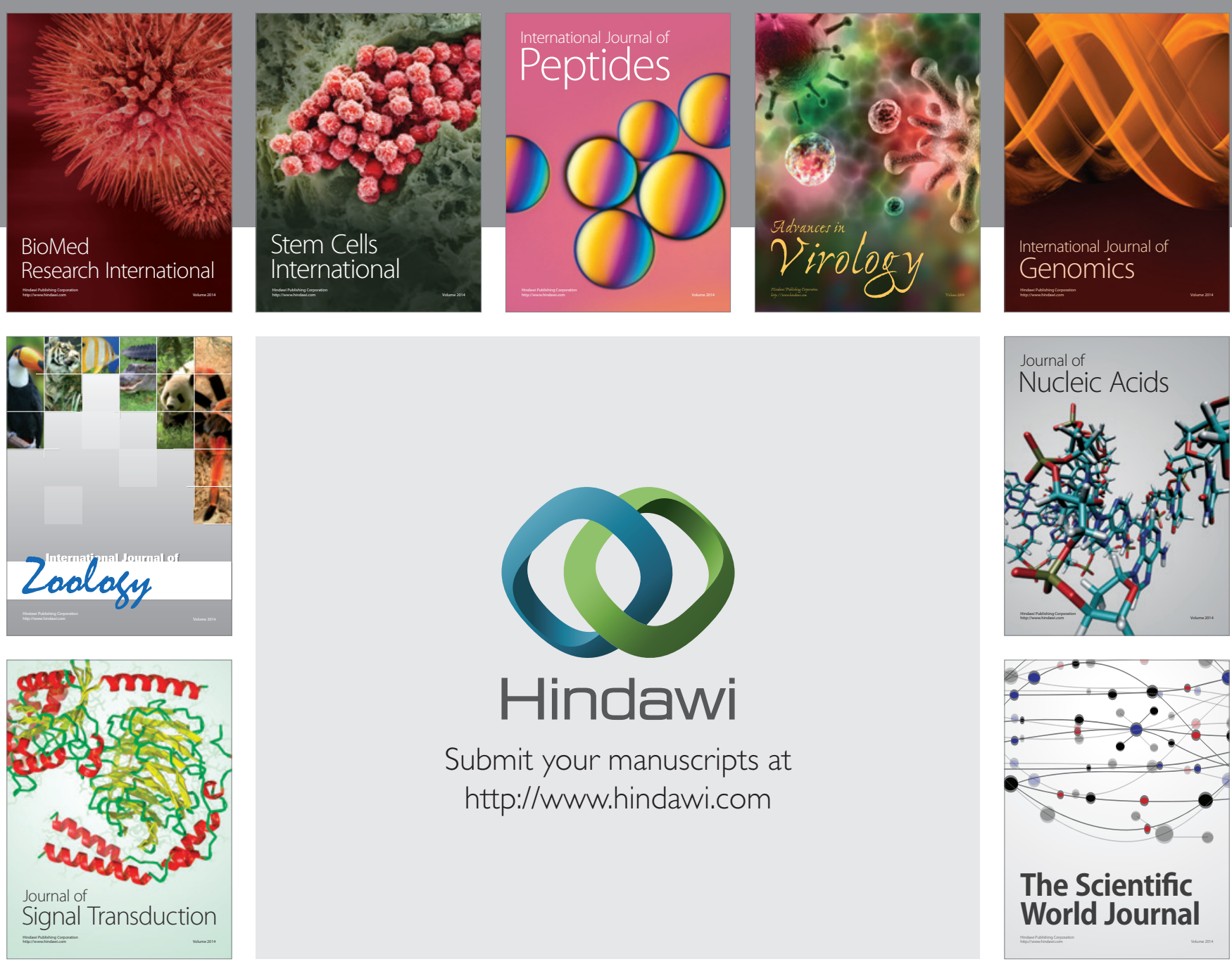

Submit your manuscripts at

http://www.hindawi.com
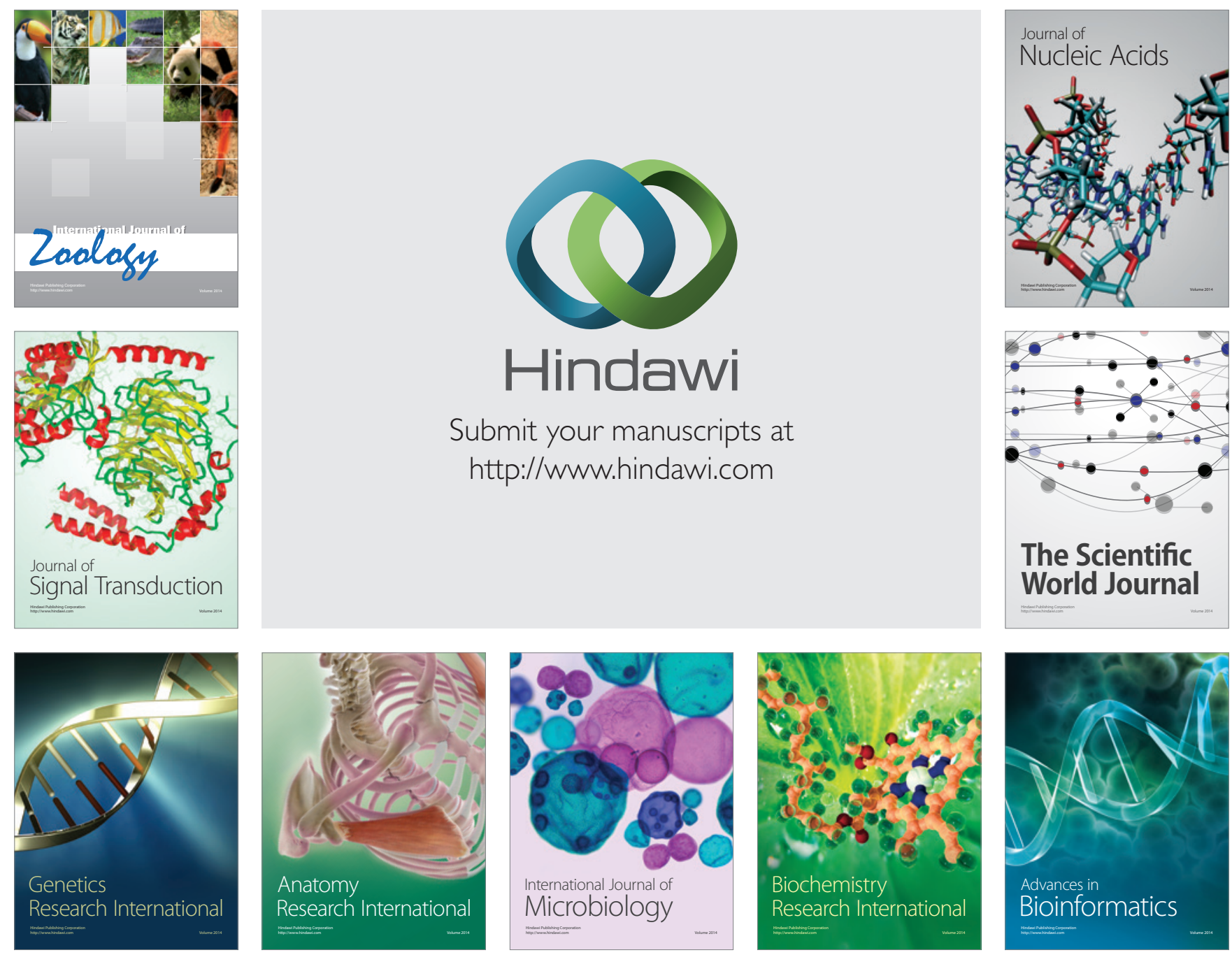

The Scientific World Journal
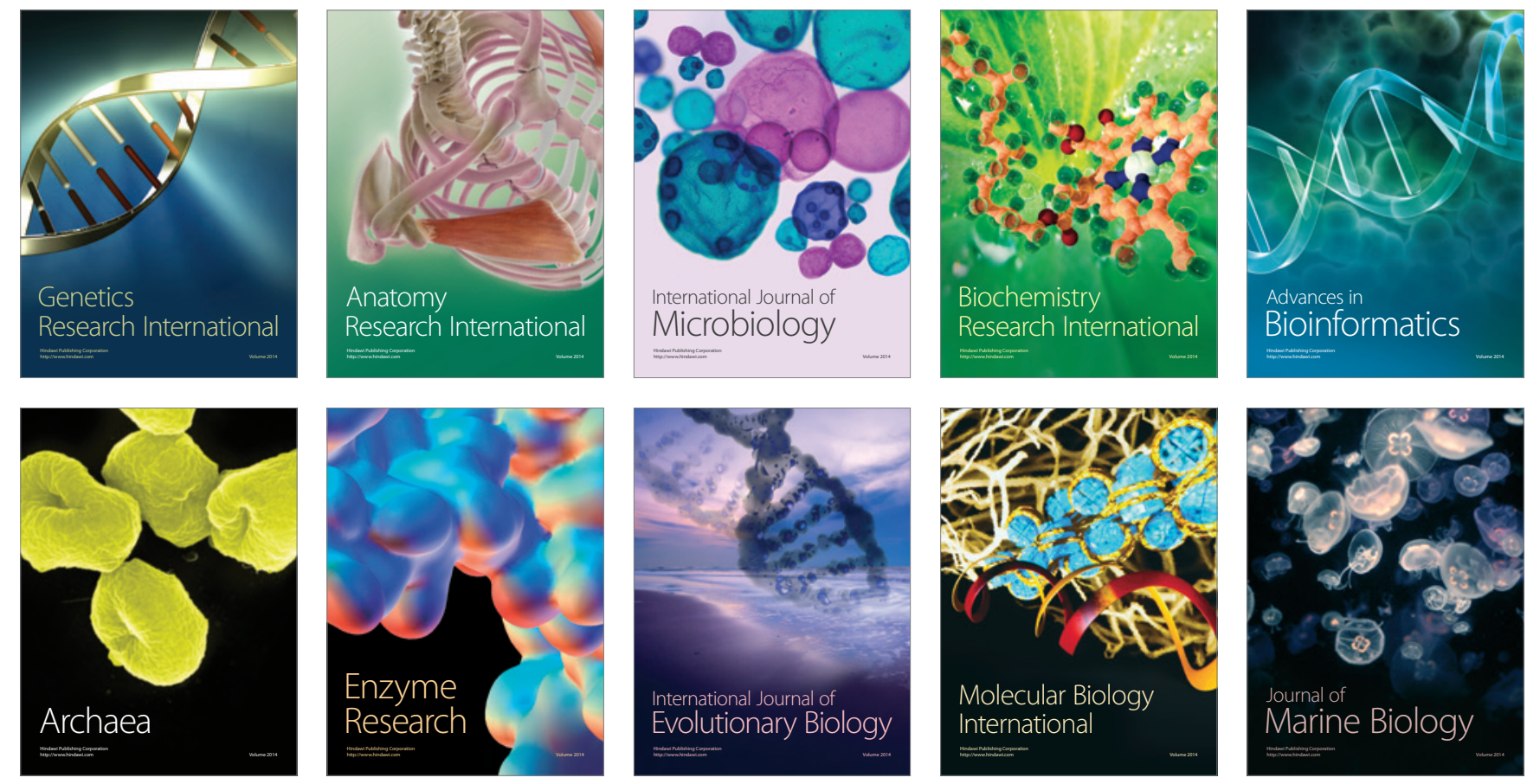